\title{
COMPARATIVE CHARACTERISTICS OF MORPHOMETRIC PARAMETERS OF ACHENES (SEEDS) FOR ADENOCAULON ADHAERESCENS MAXIM. (ASTERACEAE) IN NATIVE AND SECONDARY DISTRIBUTION RANGES
}

\author{
Vinogradova Yulia*, Gorbunov Yuri
}

N.V. Tsitsin Main Botanical Garden, Russian Academy of Sciences, Moscow, Russia

\begin{abstract}
Adenocaulon adhaerescens Maxim. is the potentially medicinal species with high antioxidant activity. Morphometric characteristics of achenes (seeds) for the species have been studied in four populations of native distribution range in Primorsky Krai (Russia). The distance from the southernmost (Popova Island) to the northernmost (buffer zone of the Ussuri Nature Reserve) of the seed collection point is about $100 \mathrm{~km}$, and this, of course, is not enough to identify correlation between geographical latitude and seed size. The environmental conditions in all four habitats are also the same - shaded paths in the forest along streams or wet plots, so that light and moisture do not seem to influence the size of the seeds. Studied plants in the fruiting phase had an average height of $83.9 \mathrm{~cm}$, with $70 \%$ of the main axis being the inflorescence and the number of lateral axes of the inflorescence ranging from 10 to 28. The size of the leaf at the base of the panicle was, on average, $8.8 \times 10.6 \mathrm{~cm}$. Plants on Russky Island have reliably smaller achenes $(5.4 \times 1.9 \mathrm{~mm})$ than in other studied populations $(6.7 \times 2.3 \mathrm{~mm})$. It was noted that the length and diameter of the achene vary in the native distribution range at a low level ( $C V=10-12 \%)$. However, we were surprised to compare our data with ones in the Moscow: in the secondary distribution range, which is almost 9 thousand kilometers away from natural habitats, the average size of seeds of this species has not changed over 70 years of introduction. In the native distribution range, seed productivity of one plant is two to three times higher than in the secondary distribution range formed in the Moscow. This is explained not by the large number of seeds in a head (5-7 seeds), but by the large number of heads formed on the plant (46-77 vr. 25-30 heads).
\end{abstract}

Keywords: Adenocaulon adhaerescens, seed, achenes, morphometric characteristic, native distribution range, Primorsky Krai

\section{Введение}

Дальневосточный вид прилипало пристающее (Adenocaulon adhaerescens Maxim.) имеет необычные для семейства Asteraceae Bercht. \& J.Presl морфологические

\footnotetext{
*Corresponding author: Yulia Vinogradova, N.V. Tsitsin Main Botanical Garden, Russian Academy of Sciences, Botanicheskaya, 4, 127276 Moscow, Russia gbsad@mail.ru
} 
признаки. На семянках отсутствует паппус, но есть крупные железки (Karrfalt and Kreitner, 1980). Краевые цветки женские, а срединные - мужские, тогда как в норме для семейства характерно как раз наличие женских цветков в центре корзинки. Род Adenocaulon относится к особой трибе Mutisieae (Funk et al., 2016).

Род Adenocaulon включает всего 6 видов: A. bicolor Hook., A. chilense Less., A. lyratum S.F. Blake, A. nepalense Bittmann, Adenocaulon adhaerescens Maxim. и A. himalaicum Edgew. Наиболее хорошо изучен последний вид, поскольку он обладает хозяйственноценными признаками. Экстракты растений A. himalaicum могут использоваться в качестве химиопрепаратов для профилактики и/или лечения рака человека (Yun et al., 2013). Его воздушные части применялись для лечения абсцессов, кровоизлияний и воспалений в корейской народной медицине, а ростки съедобны (Kwon and Lee, 2001).

Близкородственный американский вид Adenocaulon bicolor не используется столь широко, напротив, нежелателен как источник корма для оленей. Он является важным компонентом травянистого яруса в лесах из секвойи и служит растением-индикатором освещенности в лесном сообществе (Pfitsch and Pearcy, 1989a,b; Pearcy and Yang, 1998).

У всех видов рода Adenocaulon семенная продуктивность и параметры семянок не изучены. В России произрастает единственный вид - Adenocaulon adhaerescens. Его ареал занимает Приморье, Приамурье и острова Сахалин и Кунашир.

Этот вид успешно адаптировался к условиям московского климата и сформировал устойчивую инвазионную популяцию в Главном ботаническом саду Российской академии наук (Москва) и в ряде московских лесопарков. Выявлено, что этот вид может стать потенциальным источником биологически активных веществ для улучшения системы антиоксидантной защиты человека (Vinogradova et al., 2019). Ссылка на источники Наиболее высокой антиоксидантной активностью обладают молодые листочки, собранные в течение 1 - 2 недель после таяния снега, а также соцветия в стадии начала цветения (Vinogradova et al., 2019).

Во вторичном ареале морфо-биологические признаки A. adhaerescens изучены достаточно хорошо (Vinogradova and Rykhlikova, 2006; Vinogradova, 2010; Vinogradova, 2013). Одно растение формирует за вегетационный сезон около 25 - 30 корзинок, каждая из них содержит 6 - 8 цветков, и в ней образуется 5 - 7 семянок размером $6.8 \pm 0,1 \times 2.5 \pm 0,0$ мм, что составляет порядка 250 семян на одном растении (Ganina and Vinogradova, 2019). Однако в естественном ареале изменчивость биологических признаков этого вида до сих пор практически не изучена.

Цель настоящего исследования - оценить потенциальную семенную продуктивность и вариабельность размеров семянок A. adhaerescens в естественном ареале и провести сравнение с аналогичными параметрами во вторичном ареале на основе наших предыдущих исследований. 


\section{Материалы и методы}

\section{Материал исследования}

Семянки Adenocaulon adhaerescens для анализа собирали в сентябре 2019 г. в четырех местообитаниях юга Приморского края:

А) остров Русский N 42.9712 E1 31.8858;

В) остров Попова N 42.9622 Е 131.7249 ;

C) г. Владивосток, лесная территория ботанического сада N 43.2226 E 131.9932;

D) окрестности г. Уссурийска, буферная зона Уссурийского заповедника N 43.6323 E1 32.2651.

Каждый из четырех образцов семян включал все семянки, собранные с 10 растений из каждого пункта сбора. Семена хранили при комнатной температуре в течение недели. Проба для определения морфометрических признаков содержала не менее 70 семянок.

\section{Методы исследования}

На цифровом микроскопе Кеуеnce VHX-1000 определяли длину $(L)$ и диаметр семянок в самой широкой их части $(D)$. Средний объем семянки вычисляли по формуле эллипсоида $4 / 3 \pi l d^{2}$, где $l=1 / 2 \mathrm{~L}, d=1 / 2 \mathrm{D}$; форму семянок - по соотношению $L / D$.

\section{Статистическая обработка}

Данные обрабатывали в программе PAST 3.17.

\section{Резулытаты}

Семянки A. adhaerescens обратнояйцевидные, зеленого или коричневого цвета, покрыты железками с клейким экссудатом, ось соцветия также опушена железистыми волосками (Рисунок 1).

На побережье острова Русский на мысе Тобизина N 42.9574 Е 131.8768 мы обнаружили еще одну популяцию A. adhaerescens. Однако в этой популяции растения отличалась меньшей длиной соцветия (57 cм), более мелкими листьями $(7,3$ × 8,9 см) и немногочисленными корзинками (в среднем 46 шт.) с мелкими семянками. Семянки, собранные в этой популяции, мы в анализ не включали, стараясь сравнивать семенную продуктивность растений средней для вида виталитетности.

В изученных четырех популяциях вторичного ареала растения в фазе плодоношения имели в высоту в среднем 83,9 см, причем 70 \% главной оси приходилось на соцветие, а число боковых осей соцветия колебалось от 10 до 28. Размер листа в основании метелки составлял в среднем 8,8 × 10,6 см.

Размеры семянок варьировали незначительно, только образец из центральной части острова Русский достоверно отличался более мелкими (Рисунок 2) семянками. Длина семянок с острова Русский составляла 3,8 - 6,7 , $5,4 \pm 0,0)$ мм, диаметр $1,2-2,6(1,9 \pm 0,0)$ мм, объем - 11,0 $\pm 0,4$ мм $^{3}$, отношение длины семянки к ее диаметру составляло 2,2 - 3,5 (в среднем 2,8). В этой же популяции одно растение в среднем 
Vinogradova, Y., Gorbunov, Y.

Agr.bio.div. Impr. Nut., Health Life Qual., 2020, 35-43

формировало меньшее число корзинок (от 7 до 96, в среднем 46), но все равно семенная продуктивность одного растения в полтора-два раза выше, чем во вторичном ареале (276 против 162 семянок).
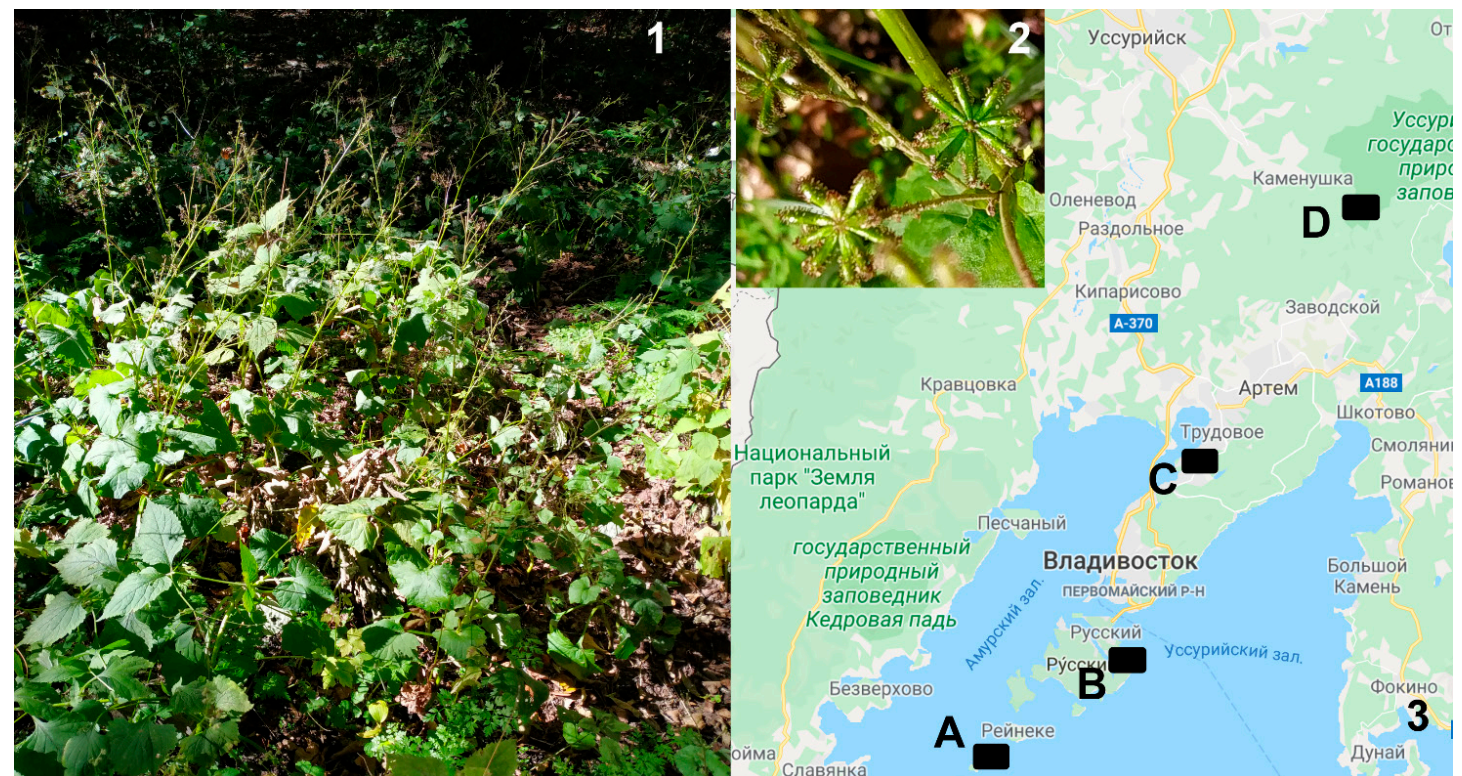

Рисунок 1 Adenocaulon adhaerescens Maxim

1 - общий вид растения; 2 - плоды; 3 - пункты сбора семян для анализа; А - остров Русский; B - остров Попова; C - Ботанический сад, г. Владивосток; D - Уссурийский заповедник

Figure 1 Adenocaulon adhaerescens Maxim

1 - habitus of the plant; 2 - fruits; 3 - collection points for seed's analysis; A - Russky Island; B - Popova Island; C - Botanical Garden, Vladivostok; D - Ussurian Reserve

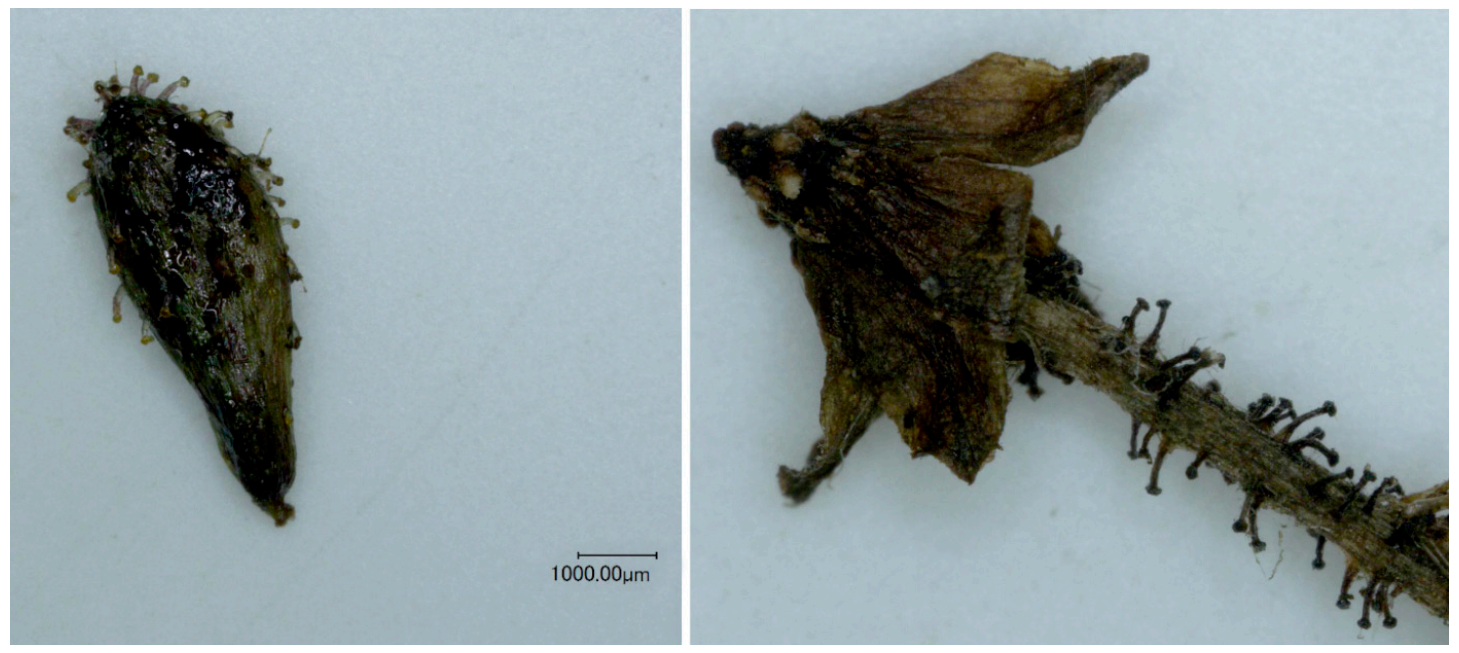

Рисунок 2 Семянка (слева) и ось соцветия (справа) Adenocaulon adhaerescens Maxim

Figure 2 Achene (left) and rachis of inflorescence (right) of Adenocaulon adhaerescens Maxim 
Семянки у растений, произрастающих в остальных трех местообитаниях, были более крупными, но достоверного различия между этими тремя пробами не выявлено (Таблица 1). Длина семянок составляет 4,2 - 8,1 (6,7 $\pm 0,0)$ мм, диаметр - 1,2 - 3,1 $(2,3 \pm 0,0)$ мм, объем - 3,0 - 32,5 $(18,5 \pm 0,4)$ мм $^{3}$, отношение длины семянки к ее диаметру составляло 2,1 - 3,9 (в среднем 3,0). Метелка содержала в среднем 77 корзинок (22 $240)$, т.е. в три раза больше, чем во вторичном ареале в Москве, а максимальное число корзинок на растении достигало 240 шт.! Семенная продуктивность одного растения составляла в среднем 462 семянки, что также в три раза выше, чем во вторичном ареале.

Таблица 1 Морфометрические признаки семянок Adenocaulon adhaerescens Maxim.

Table 1 Morphometric characteristics of achenes for Adenocaulon adhaerescens Maxim.

\begin{tabular}{lcccccc}
\hline Местообитание & \multicolumn{3}{c}{$\boldsymbol{L} \mathbf{( m m )}$} & \multicolumn{3}{c}{$\boldsymbol{D}(\mathbf{m m})$} \\
\cline { 2 - 6 } & $\bar{x} \pm \mathrm{S}_{x}$ & $\min$ & $\max$ & $\bar{x} \pm \mathrm{S}_{x}$ & $\min$ & $\max$ \\
\hline A & $5,4 \pm 0,1$ & 3,8 & 6,7 & $1,9 \pm 0,02$ & 1,2 & 2,6 \\
В & $6,5 \pm 0,1$ & 5,4 & 7,4 & $2,3 \pm 0,01$ & 1,8 & 3,1 \\
C & $6,6 \pm 0,1$ & 5,0 & 8,1 & $2,3 \pm 0,01$ & 1,7 & 2,9 \\
D & $7,0 \pm 0,1$ & 4,2 & 8,0 & $2,2 \pm 0,01$ & 1,2 & 2,8 \\
\hline \hline Местообитание & & $\boldsymbol{L} / \boldsymbol{D}$ & & & $\boldsymbol{V}\left(\mathbf{m m}^{\mathbf{3}}\right)$ & \\
& $\bar{x} \pm \mathrm{S}_{x}$ & $\min$ & $\max$ & $\bar{x} \pm \mathrm{S}_{x}$ & $\min$ & $\max$ \\
\hline A & $2,8 \pm 0,03$ & 2,2 & 3,5 & $11,0 \pm 0,4$ & 3,1 & 21,5 \\
В & $2,8 \pm 0,02$ & 2,1 & 3,4 & $18,9 \pm 0,6$ & 8,8 & 31,7 \\
C & $2,9 \pm 0,02$ & 2,4 & 3,8 & $19,2 \pm 0,08$ & 8,8 & 31,8 \\
D & $3,2 \pm 0,03$ & 2,8 & 3,9 & $17,6 \pm 0,06$ & 3,0 & 32,5 \\
\hline
\end{tabular}

Примечание: А - остров Русский; В - остров Попова; C - Уссурийский заповедник; $D$ - Ботанический сад, г. Владивосток; $L$ - длина; $D$ - ширина; $L / D$ - отношение длины семянок к ширине; $V$ - объем семянки; $\min$ минимальное значение; max - максимальное значение; $\bar{x}$ - среднее значение; $S_{x}$ - стандартное отклонение

Следовательно, размер семянок у растений из вторичного ареала $(6,8 \pm 0,1 \times 2,5 \pm 0,0)$ не имеет значительных отличий от размеров семянок растений, произрастающих в естественном ареале.

У всех четырех образцов изменчивость морфометрических признаков была низкой: коэффициент вариации составлял для длины семянок 9 \%, диаметра семянок - 12 \%, отношения $L / D$ - $11 \%$ Объем семянок варьировал на среднем уровне: у образца с острова Русский 28 \%, у сборного образца из остальных трех местообитаний - 31 \%. По форме семянок образцы также не различались (Рисунок 3).

Следовательно, размер семянок у растений из вторичного ареала $(6,8 \pm 0,1 \times 2,5 \pm 0,0)$ не имеет значительных отличий от размеров семянок растений, произрастающих в естественном ареале. 
Vinogradova, Y., Gorbunov, Y.

Agr.bio.div. Impr. Nut., Health Life Qual., 2020, 35-43

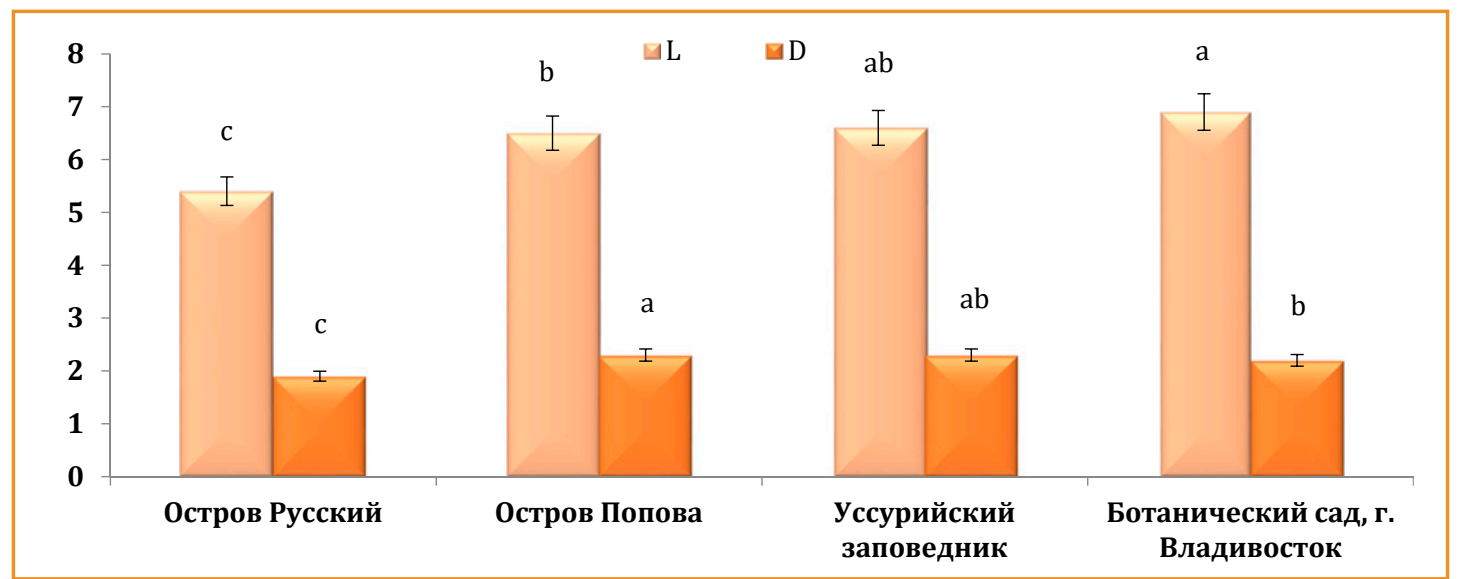

Рисунок 3 Морфометрические признаки семянок Adenocaulon adhaerescens Maxim $L$ - длина, мм; $D$ - диаметр, мм

Figure 3 Morphometric characters of achenes of Adenocaulon adhaerescens Maxim $L$ - lenght, $\mathrm{mm}$; $D$ - diameter, $\mathrm{mm}$

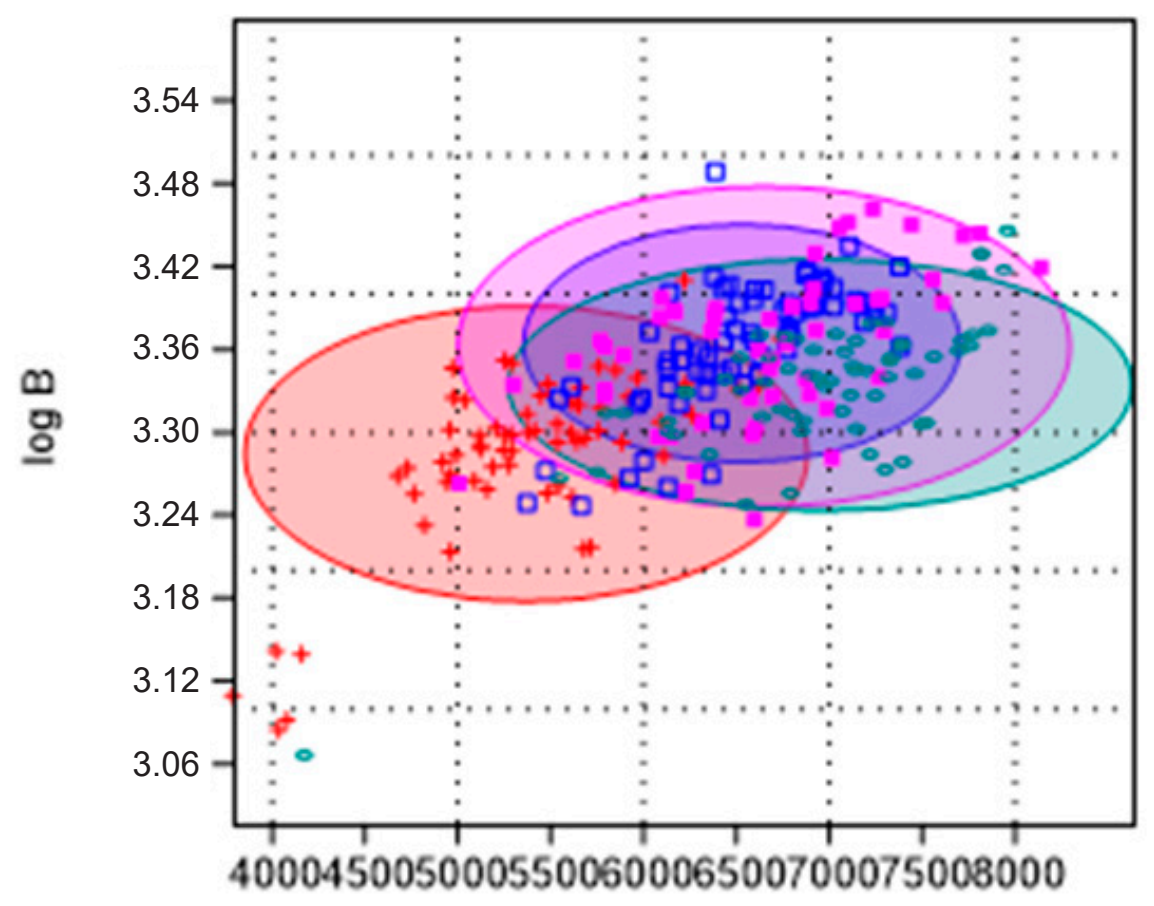

Рисунок 4 Форма семянок $L / D$ (ось $y$ ) и средний объем семянок $V$ (ось $x$, мм $^{3}$ ) Adenocaulon adhaerescens Maxim в различных местообитаниях Приморского Края красный цвет - остров Русский; синий цвет - остров Попова; фиолетовый цвет - Уссурийский заповедник; зеленый цвет - Ботанический сад, г. Владивосток

Figure 4 Shape of achenes $\left(L / D, y\right.$-axis) and average $V, \mathrm{~mm}^{3}\left(4 / 3 \pi L D^{2}, x\right.$-axis $)$ of Adenocaulon adhaerescens Maxim in the different habitats in Primorsky Krai

red - Russky Island; blue - Popova Island; violet - Ussurian Reserve; green - Botanical Garden, Vladivostok 


\section{Обсуждение}

Подобно другим видам рода Adenocaulon, семянки A. adhaerescens имеют железистые волоски и поэтому легко рассеиваются, прилипая к одежде человека или шерсти животных (Redonda-Martínez et al., 2020). К сожалению, нет литературных данных о размерах семянок близкородственных видов Adenocaulon, однако для множества других видов отмечено значительное варьирование размеров семянок в зависимости от экологических факторов (Massimi, 2018; Pinto et al., 2018). Что касается оценки характеристик природных и инвазионных популяций в полевых условиях, то исследований здесь довольно много. Интерес к этому вопросу возрос после появления гипотезы увеличения конкурентной способности вида EICA, которая утверждает, что после избавления от природных врагов, во вторичном ареале эволюция заносных видов ускоряется. Если это происходит в результате распределения ресурсов между ростовыми и защитными механизмами, естественный отбор должен идти в сторону создания менее защищенных, но более конкурентоспособных генотипов в условиях вторичного ареала (Blossey and Nötzold, 1995). Основной путь проверки этой гипотезы состоит в сравнении потомков природных и интродукционных популяций в устойчивых условиях среды. Однако работы, в основном, касаются размеров популяций и высоты растений, а полученные результаты противоречивы. Тем не менее, семь из девяти сравнений размеров и плодовитости растений показывают, что эти параметры выше во вторичном ареале (Khoroon, 2014).

Расстояние от самого южного (остров Попова) до самого северного (буферная зона Уссурийского заповедника) пункта сбора семян A. adhaerescens составляет по прямой около 100 км, и это, разумеется, недостаточно, чтобы уловить связь между географической широтой местности и размером семянок. Экологические условия произрастания растений во всех четырех местообитаниях также однотипны - это затененные тропинки в лесу вдоль ручьев или топких мест, так что на размер семянок свет и влага, по-видимому, не оказывают влияния. Отличие популяции с острова Русский по наиболее мелким семянкам мы объясняем расположением популяции недалеко от морского побережья и сильным антропогенным воздействием (уплотнением грунта многочисленными туристами).

Однако удивительным для нас оказался факт, что и в Москве, во вторичном ареале, удаленном от естественных местообитаний почти на 9 тыс. километров, средний размер семянок этого вида за 70 лет интродукции не изменился.

\section{Выводы}

Размеры семянок у растений A. adhaerescens в естественном ареале варьируют в зависимости от местообитания: на острове Русский семена достоверно мельче $(5,4 \times 1,9$ мм), чем в остальных изученных популяциях $(6,7 \times 2,3$ мм). В естественном ареале семянки $A$. adhaerescens не различаются по параметру $L / D$, а также по коэффициенту вариации параметров $L$ и $D$. Растения A. adhaerescens во вторичном ареале в Москве отличаются от растений естественного ареала не по размерам семянок 
и не по числу семянок в корзинке, а по числу формирующихся на генеративном побеге корзинок: в Москве число корзинок в среднем 25 - 30, тогда как в естественном ареале 46 - 77. Таким образом, семенная продуктивность одного растения в естественном ареале в два-три раза выше, чем во вторичном ареале.

\section{Благодарности}

Исследование выполнено в рамках Программы Президиума РАН № 0111-2018-0003 41 «Биоразнообразие природных систем и биологические ресурсы России» при частичной финансовой поддержке гранта РФФИ 19-54-26010.

\section{Литература}

BLOSSEY, B., NÖTZOLD, R. 1985. Evolution of increased competitive ability in invasive nonindigenous plants: a hypothesis. In J. of Ecology, vol. 83, p. 887-889.

FUNK, V.A., PASINI, E., BONIFACINO, J.M., KATINAS, L. 2016. Home at last: the enigmatic genera Eriachaenium and Adenocaulon (Compositae: Mutisioideae; Mutisieae; Adenocaulinae). In PhytoKeys, vol. 60, p. 1-19. http://dx.doi.org/10.3897/phytokeys.60.6795

GANINA, A., VINOGRADOVA, YU. 2019. Var'irovanie morfologicheskih priznakov Adenocaulon adhaerescens (Asteraceae) vo vtorichnom areale [Variability of morphological characters of Adenocaulon adhaerescens (Asteraceae) in a secondary distribution range]. In Environment and Human: Ecological Studies, vol. 9(2), p. 131-144. http://dx.doi.org/10.31862/2500-2961-2019-92-131-144 [In Russian]

KARRFALT, E.E., KREITNER, G.L. 1980. The development of the glandular trichomes of Adenocaulon bicolor. In Canadian Journal of Botany, vol. 58, p. 61-67.

KHOROON, L.V. 2014. Problemy invazionnoj ekologii rastenij v zarubezhnoj nauchnoj literature. [Problems of invasive plant's ecology in foreign science literature]. In Udmurt university newsletter, vol. 3, p. 64-77 [In Russian].

KWON, H.C., LEE, K.R. 2001. An acetylene and a monoterpene glycoside from Adenocaulon himalaicum. In Planta Medica, vol. 67(5), p. 482-484. http://dx.doi.org/10.1055/s-2001-15806

MASSIMI, M. 2018. Impact of seed size on seeds viability, vigor and storability of Hordeum vulgare (L.). In Agric. Sci. Digest., vol. 38(1), p. 62-64.

PEARCY, R.W., YANG, W. 1998. The functional morphology of light capture and carbon gain in the Redwood forest understory plant Adenocaulon bicolor Hook. In Functional Ecology, vol. 12(4), p. 543-552. https://doi.org/10.1046/j.1365-2435.1998.00234.x

PFITSCH, W.A., PEARCY, R.W. 1989a. Steady-state and dynamic photosynthetic response of Adenocaulon bicolor (Asteraceae) in its redwood forest habitat. In Oecologia, vol. 80, p. 471-476. https://doi. org/10.1007/BF00380068

PFITSCH, W.A., PEARCY, R.W. 1989b. Daily carbon gain by Adenocaulon bicolor (Asteraceae), a redwood forest understory herb, in relation to its light environment. In Oecologia, vol. 80, p. 465-470. https://doi.org/10.1007/BF00380067

PINTO, C.A.G., KRZYANOWSKI, F.C., FRANÇA-NETO, J.B., DOURADO-NETO D., BARBOZA DA SILVA, C., MARCOS-FILHO, J. 2018. Relationship between size and physiological potential of soya bean seeds under variations in water availability. In Seed Science and Technology, vol. 46(3), p. 497-510. https://doi.org/10.15258/sst.2018.46.3.07

REDONDA-MARTÍNEZ, R., TERRAZAS, T., ROJAS-LEAL, A. 2020. Morpho-anatomy of the cypselae of native species of Mutisieae (Asteraceae) from Mexico. In Phytotaxa, vol. 436(1), p. 1-20. http:// dx.doi.org/10.11646/phytotaxa.436.1 
VINOGRADOVA, YU. 2010. The biology of Adenocaulon adhaerescens in initial invasive population. In $6^{\text {th }}$ NEOBIOTA Conference Biological invasions in a changing world from science to management. Copenhagen, p. 184. ISBN: 978-87-993976-0-0

VINOGRADOVA, YU. 2013. Adenocaulon adhaerescens Maxim. Biologiya i ekologiya rasteniy rossiyskogo Dalnego Vostoka [Biology and ecology of plants in Russian Far East]. Ussuriysk: Far East State University, p. 99-106 [In Russian].

VINOGRADOVA, YU., GANINA, A., VERGUN, O. 2019. Possibility of using alien Adenocaulon adhaerescens Maxim. (Asteraceae) as the medicine plant. In 4th International scientific Conference Agrobiodiversity for improve the Nutrition, Health and Quality of Human and Bees Life. Nitra, p. 149. ISBN 978-80-552-2037-6.

YUN, J.H., LEE, S.B., KANG, K., LEE, E.H., LEE, H.J., JUNG, S.H., NHO, C.W. 2013. Bifunctional chemopreventive effects of Adenocaulon himalaicum through induction of detoxification enzymes and apoptosis. In Journal of Medicinal Food, vol. 16(8), p. 701-710. https://doi.org/10.1089/jmf.2012.2625 